\title{
EXPANDING THE BASE: A CASE FOR INCREASED INTERPROFESSIONAL Collaboration in Public Health Law and Policy
}

Heather A. McCabe, ${ }^{*}$ Marea K. Kinney, ${ }^{* *}$ Stephanie Q. Quiring, ${ }^{* * *}$ Doug Jerolimov ****

TABLE OF CONTENTS

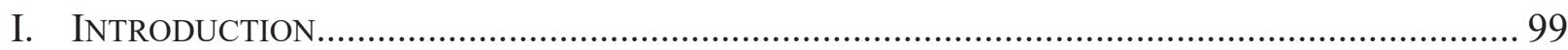

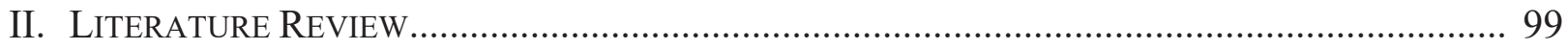

A. Population Health

B. Growth of Programs Working Towards Increased Collaboration between Public Health and Law

C. Course: Seminar in Public Health Law and Policy in an Interprofessional Setting

III. METHODOLOGY.... 103
A. Research Question
B. Research Design.
C. Study Participants
D. Measures

IV. INTERPROFESSIONAL COLLABORATIVE COMPETENCIES ATTAINMENT SURVEY 104
A. Individual Group Evaluations
B. Data Collection and Analysisx

V. RESULT. 107

A. Interprofessional Collaborative Competencies Attainment Survey ("ICCAS")

1. Theme 1: Professional Hegemony Exists Between the Professional Students

2. Theme 2: Students Perceive Professional Content Expertise as the Most Important Knowledge

* Heather A. McCabe, JD, MSW; Associate Professor, Indiana University School of Social Work; Adjunct Professor, Robert H. McKinney School of Law and Richard M. Fairbanks School of Public Health

** Marea K. Kinney MSW, PhD Student \& Research Assistant; Indiana University School of Social Work

*** Stephanie Q. Quiring, JD, MSW, PhD Student, Indiana University School of Social Work **** Doug Jerolimov, JD, Visiting Lecturer \& PhD Candidate; Indiana University School of Social Work 
3. Theme 3: Learning Collaborative Skills Needs to be Intentional and Does not Occur Effectively Simply by Working Together

\title{
B. Challenges to Interprofessional Collaboration Among Students
}

\begin{abstract}
Despite the need for effective collaboration between competent practitioners to create comprehensive policy that is informed by multiple professions, minimal literature exists on interprofessional education focused on the macro arena. In response to the identified need, an interprofessional course was developed to provide social work, law, and public health graduate students knowledge of social determinants of health and policy in order to function in the macro arena. The course was piloted in 2015 with 10 students from social work, law, and public health. Components of the interprofessional course are described. An interprofessional team of researchers from social work, law, and the center for teaching and learning evaluated the interprofessional course to answer the following questions: 1) "How do students understand their role as future professionals?" and 2) "How do student navigate the collaborative process within IPE?" Evaluation of the course was guided primarily by a critical discourse analysis ("CDA") of individual group evaluations. Data analysis also included Interprofessional Collaborative Competencies Attainment Survey ("ICCAS") pre- and post-tests. A paired sampled t-test was conducted for the ICCAS summary scores as well a comparison of mean and standard deviation for summary scores of the six subscales. The results indicated that students increase their collaborative competency during the course; however, greater emphasis is needed in specific collaborative skills. The CDA produced three primary themes: 1) Professional Hegemonx Exists Between the Professional Students, 2) Students Perceive Professional Content Expertise as the Most Important Knowledge, and 3) Learning Collaborative Skills Needs to be Intentional and Does not Occur Effectively Simply by Working Together. The themes as well as strengths and challenges to collaboration from a student perspective are discussed.
\end{abstract}

Keywords: Interprofessional education, interprofessional collaboration, course evaluation, critical domain analysis, graduate students 


\section{INTRODUCTION}

In May 2011, The Interprofessional Education Collaborative ("IPEC") released a seminal document laying out core competencies for interprofessional collaborative practice. ${ }^{1}$ Interprofessional education "occurs when students from two or more professions learn about, from, and with each other to enable effective collaboration and improve health outcomes," and this method of learning has been growing in popularity in health education in recent years. ${ }^{2}$ IPEC, made up of representatives from six national professional health and public health associations, provided a road map for a much-needed area of knowledge to navigate interprofessional collaboration and provided a long-needed legitimacy to the issue of interprofessional practice. Since that time, the Agency for Healthcare Research and Quality ("AHRQ") and other federal research institutions, as well as private foundations, such as the Macy Foundation and Robert Wood Johnson Foundation, have put significant resources toward building the field of interprofessional education and the practice in the health care system. ${ }^{3}$ In 2016 , IPEC, which had expanded to include nine additional professional organizations, updated the interprofessional competencies. ${ }^{4}$ The update created a renewed and expanded emphasis on population health. ${ }^{5}$

\section{LITERATURE REVIEW.}

\section{A. Population Health}

Population health is distinct from health care. In population health, the emphasis is on the health of the population and not any one individual. Tools go beyond improvement or interventions at the bedside and can include changes to the environment or to policies that impact the overall health of the population. Public health interventions are primarily aimed at impacting population health. The seminal report of the 1988 Institute of Medicine entitled The Future of Public Health described a public health system in need of overhaul defining public health as "what we as a society do collectively to assure the conditions in which people can be healthy." 6 The study has been used as a jumping off point for scholars and practitioners alike to work at the policy level on issues impacting the health of the population. In order to move forward in population health, addressing social determinants of health ("SDOH") will be critical. SDOH are "[t]he conditions in which

1 Interprofessional Education Collaborative, Core Competencies for Interprofessional collaborative Practice, (2011), http://www.aacn.nche.edu [https://perma.cc/8YVG-8JP8].

${ }^{2}$ World Health Organization ("WHO"), Framework for Action on Interprofessional Education \& Collaborative Practice, at 10, 14, (2010), http://apps.who.int/iris/bitstream [http://perma.cc/8ZEH-H8X6].

3 Interprofessional Education and Teamwork, THE JOSIAH MACY JR. Foundation http://macyfoundation.org/ [https://perma.cc/V5AK-FSC2] (last visited Feb. 16, 217); see also Advancing Partners and Practice through Public Health Law, ROBERT WOOD JOHNSON Foundation http://www.rwjf.org/ [https://perma.cc/2ZKZ-ZMEK] (last visited Feb. 16, 2017).

${ }^{4}$ Interprofessional Education Collaborative, supra note 1.

${ }^{5}$ Id.

${ }^{6}$ Inst. Of Med., The Future of the Public's Health in the 21 $1^{\text {st }}$ Century, NCBI (2002), http://www.ncbi.nlm.nih.gov/books/NBK221233/ [https://perma.cc/5QE8-CZ7Z]. 
people are born, grow, live, work and age." ${ }^{7}$ As interprofessional efforts move forward, there will be a need to increase the emphasis on the policies that increase our ability to have an impact on social determinants of health. It goes beyond ensuring "someone" is working on the policy. The authors propose here that we build on the effort begun in the field of public health law to ensure that a broad interprofessional approach to policy-making is achieved.

Public health law has experienced a kind of resurgence or a revitalization in recent decades. ${ }^{8}$ Public health law is defined by Gostin as:

[T] he study of the legal powers and duties of the state, in collaboration with its partners (e.g., health care, business, the community, the media, and academe), to ensure the conditions for people to be healthy (to identify, prevent, and ameliorate risks to health in the population), and of the limitations on the power of the state to constrain for the common good the autonomy, privacy, liberty, proprietary, and other legally protected interests of individuals. The prime objective of public health law is to pursue the highest possible level of physical and mental health in the population, consistent with the values of social justice. ${ }^{9}$

Inherent in the definition is a recognition of the multitude of systems impacting the health of the population. In addition to the current professions of law and public health, the authors suggest also including social scientists in the work towards improving public health policy-in this collaboration, social workers were included. Social work and other social scientists have specific expertise in systems theory and an ecological perspective of the environment in which health and public health services are delivered. ${ }^{10}$

\section{B. Growth of Programs Working Towards Increased Collaboration between Public Health and Law}

${ }^{7}$ World Health Org., Closing the gap in a generation: Health equity through action on the social determinants of health, Final Report of the Commission on Social Determinants of Health (2008), http://apps.who.int [https://perma.cc/ZGJ5-LC69].

${ }^{8}$ Thaddeus M. Pope, The Slow Transition of U.S. LAW TOWARd a Greater EMPhasis ON Prevention, (Halley S. Faust \& Paul T. Menzel 2011).

${ }^{9}$ Lawrence O. Gostin, A Theory and Definition of Public Health Law, 10 J. Health CARE L. \& POL'Y 1-12 (2007).

${ }^{10}$ Antony Sparkes, The Strengths Model: A Recovery-Oriented Approach to Mental Health Services, 3rd ed. 42(1) BRITISH J. SOC. WORK 190-192 (2012); see also Heather A. McCabe \& W. Patrick Sullivan, Social Work Expertise: An Overlooked Opportunity for Cutting-Edge System Design under the Patient Protection and Affordable Care Act, 40(2) HEALTH Soc. WorK 155-157 (Feb. 16, 2015); see also Dennis Saleebey, The Strengths Perspective in Social Work Practice (Allyn \& Bacon, 6th ed. 2012). 
The Public Health Law Program at the $\mathrm{CDC}^{11}$ and foundations such as the Robert Wood Johnson Foundation have been supporting work to partner public health researchers with legal researchers in an attempt to better link policies with health outcomes. ${ }^{12}$ The work in this area is a necessary step to improve abilities to make effective public health policy. Competence of the relationship between law and the healthcare system requires an understanding of the dynamic exchanges of individuals, legislation and policy, and social justice. ${ }^{13}$ Scott Burris, the Director of the RWJF funded Public Health Law Research Program, has been an advocate of legal research in collaboration with public health researchers. In a 2011 article, he asserted that, "Health researchers have to let law out of its box in the macro-social context and start including legal variables and hypotheses on an equal footing with other social and attitudinal factors influencing health behavior." 14 The inclusion of social scientists, here social work, would bring additional expertise in these areas. Social scientists have been working in the field of social determinants of health since before the term had been created. ${ }^{15}$ Including social scientists at the table in the policy making process will bring another set of skills and perspectives ensure that the policies will work on the ground and with already existing structures which may be outside the expertise of those already involved.

Macro social work is on the continuum of social work writ large. It has been illustrated by Netting as including multiple domains: Problem, population, and arena, which occur in a political and policy context (Figure 1). ${ }^{16}$

11 CTR. for Disease Control and Prevention, Public Health Law Program, https://www.cdc.gov/phlp/ [http://perma.cc/Y689-RDJ2] (last updated May 4, 2016).

12 Public Health Law Research Making the Case for Laws that Improve Health, http://publichealthlawresearch.org/ [https://perma.cc/X6S7-SLVW].

${ }^{13}$ Emily A. Benfer et al., Advancing Health Law \& Social Justice in the Clinic, the Classroom, and the Community. AnNals of Health Law, 21, 237-56 (2012).

${ }^{14}$ Scott Burris, Law in a Social Determinants Strategy: A Public Health Law RESEARCH PERSPECTIVE 22-27 (2011).

15 Michael Reisch \& Janice Andrews, The Road Not Taken: A History of Radical SOCIAL WORK IN THE UNITED STATES (2002).

${ }^{16}$ Ellen F. Netting et al., Social Work Macro Practice, (5th ed. 2012). 
Figure ${ }^{17}$

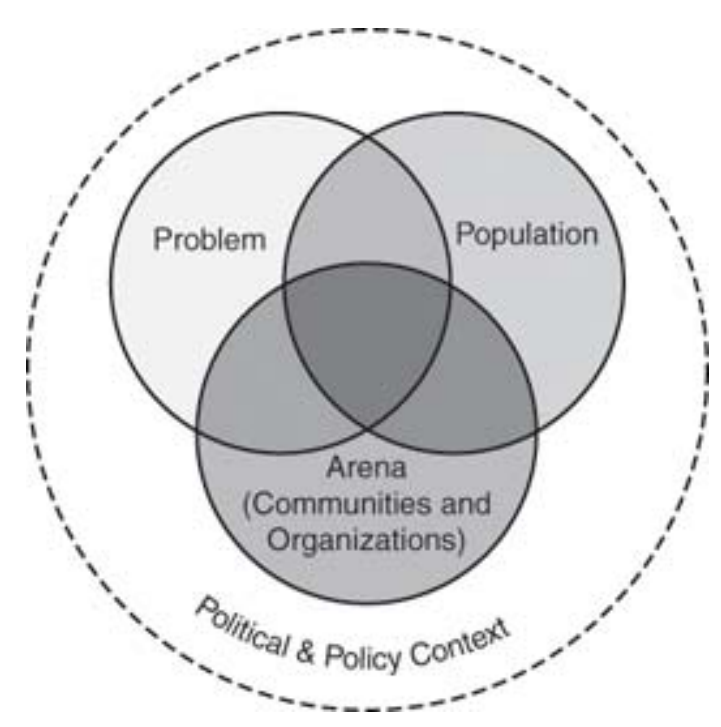

Social workers working in the macro arena bring expertise in social interaction, system design, and advocacy, as well as a broad knowledge of the human behavioral social environment. ${ }^{18}$ Partnering these sets of knowledge and skills with those in public health and law to engage in the process of public health policy, can provide another perspective from which improved policymaking can occur. For this partnering to occur, effective and efficient collaborative skills are necessary.

Inclusion of social work is not a new idea. Social work expertise in the macro arena includes an ethic directed at social justice, a component of Gostin's definition of public health law. ${ }^{19}$ Rand commends the NASW Code of Ethics for defining social justice and the wide application in practice that could benefit law. ${ }^{20}$ Recently, medical-legal partnerships ("MLPs") have been created where interprofessional teams work on legal and social issues impacting health outcomes. ${ }^{21}$ "The MLP model works to achieve three core goals: (1) provide direct legal assistance to individuals, (2) transform healthcare and legal institution practice, and (3) impact policy and effectuate systemic change to improve population health."22 Many, though not all, MLPs include legal, social work, and public health professionals. It is a concept whose time has come.

${ }^{17}$ Id.

${ }^{18} \mathrm{Id}$.

19 Lawrence O. Gostin, A Theory and Definition of Public Health Law, Public Health Law Power, Duty, Restraint, (PG. 4-5) (2 ${ }^{\text {nd }}$ ed. 2008).

20 Spencer Rand, Teaching Law Students to Practice Social Justice: An Interdisciplinary Search for Help Through Social Work's Empowerment Approach. 13 CLINICAL L. REV. 459, 47475 (2006).

21 American Medical Colleges, Medical-Legal Partnership Logic Model, https://www.aamc.org [https://perma.cc/3BDR-W9ZU].

${ }^{22}$ Daniel Atkins, et al., Medical-Legal Partnership and Healthy Start: Integrating Civil Legal Aid Services into Public Health Advocacy, 35 J. OF Legal Medicine 195, 200 (2014). 
If we are to have a competent workforce, we must train the students in a way that models the work we wish to see. To that end, with the help of a Robert Wood Johnson Foundation Public Health Law Fellowship, the authors created a pilot course with law, public health, and social work students. Students from graduate programs in social work, law, and public health worked in an experiential setting to create policy responses to questions generated by community agencies. Though there is still work to do, the evaluation of the model suggests a promising approach to a more inclusive model of public health law and policy creation.

\section{Course: Seminar in Public Health Law and Policy in an Interprofessional Setting}

Research has suggested that interprofessional skills are necessary for effective work in the health arena. ${ }^{23}$ The authors suggest the macro arena is no exception. The course provided students with an opportunity to build on public health law and policy knowledge by learning about working as a part of an interprofessional team in case-based and experiential learning environments. Experiential sites in hospitals and medical-legal partnership non-profits provided policy issues on which the students worked. Through team-based work on these policies, the course sought to provide students with opportunities to build skills needed to understand, analyze, apply and develop public health law and policy.

This interprofessional course was designed to help develop professionals who can: 1) understand and analyze public health law and regulations as appropriate to the discipline; 2) work as a part of a team of public health, social work, and legal professionals to analyze different options for action; and 3) learn from a team of public health, social work, and legal professionals to better understand social determinants of health in order to advocate for clients and more effective public health policies.

\section{Methodology}

\section{A. Research Question}

The study evaluated the interprofessional course to answer the following questions: 1) "How do students understand their role as future professionals?" and 2) "How do student navigate the collaborative process within IPE?"

\section{B. Research Design}

In response to the growing need for IPEC in the macro arena, and the dearth of courses providing the necessary skills, the authors created an interprofessional course focused on social determinants of health in the fall of 2015. The course targeted students in graduate law, public health, and social work programs. A systems-level approach was used drawing from each professional perspective on organizational, community, and policy change. At the completion of the course an interprofessional team of researchers from law, social work, and the center for teaching and learning provided a qualitative evaluation to enhance subsequent iterations of the course and provided insight into interprofessional education at a systems-level.

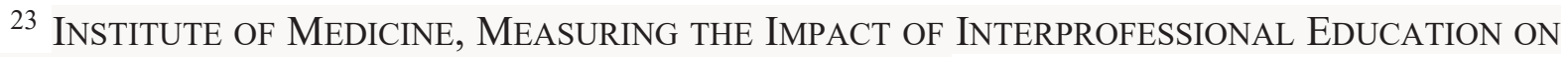
Collaborative Practice and Patient Outcomes (2015). 


\section{Study Participants}

The authors used availability sampling with inclusion criterion that participants were current graduate students at the university enrolled in the course described above. Recruitment for the course included listserv emails to law, social work, and public health, as well as flyers posted at the schools of public health and law. Internal Review Board approval was received for all course products to be used for the evaluative study.

Students were assigned to groups of three to four with a representative from each profession as illustrated below in Table $1 .{ }^{24}$ Groups collaborated with selected community organizations to identify a policy related to social determinants of health for analysis and suggested improvements. At the end of the semester, students presented a deliverable-generally white papers and issue briefs-to the community organization for use in policy advocacy. As a part of the course, students recorded progress in content and process. Tools used to assess student outcomes and course evaluation include: Professional reflection journals, StrengthsFinder 2.0, reflection on use in practice, deliverable for the agency, evaluation of team competence (self and teammates), Interprofessional Collaborative Competencies Attainment Survey ("ICCAS"), class participation, and a concept mapping project.

\begin{tabular}{lllll}
\hline & MSW & $\begin{array}{l}\text { MSW/MP } \\
\text { H }\end{array}$ & JD/MPH & JD \\
\hline Group 1 & 2 & & & 1 \\
Group 2 & 2 & 1 & 1 & \\
Group 3 & $2^{*}$ & & & 1 \\
Total & 5 & 1 & 1 & 2 \\
\hline
\end{tabular}

Table 1 Interprofessional Students Groups*

\section{Measures}

From the multiple products, the ICCAS pre-tests and post-tests and individuals' group evaluations were chosen from the class for the study because of their personal insight into change in competencies and the quality of collaborative relationships between professions. These evaluation measures included both the content and process of the collaborative experience over the course of the semester and will be discussed below.

\section{INTERPROFESSIONAL COLLABORATIVE COMPETENCIES ATtAINMENT SURVEY}

The ICCAS is a self-reported survey measuring interprofessional care competencies ("IPC"). The foundation of the ICCAS is a set of interprofessional care competencies: communication, collaboration, roles and responsibilities, conflict resolution and management, and team

\footnotetext{
${ }^{24}$ See Table 1

* One student did not complete an individual group evaluation.
} 
functioning. ${ }^{25}$ The survey consists of twenty questions answered on a seven-point Likert scale, ranging from "strong disagreement" to "strong agreement." The validity and reliability of this scale has been documented with a high level of internal consistency (pre-test: $\alpha=.961$, post-test: $\alpha=$ $.981){ }^{26}$

\section{A. Individual Group Evaluations}

After completion of group projects, each student completed a group evaluation. Eight openended questions asked students about their individual experiences working in collaborative groups-identifying strengths, challenges, professional roles, future work, growth, and course comments. $^{27}$

1. How was communication in your group?

2. How did your knowledge of Law/policies change?

3. How did your knowledge of Social determinants of health change?

4. Provide three examples of how consulting other professions will enhance your understanding and knowledge in the future.

5. How did you and your team learn about to effectively communicate?

6. How does social work, public health, and law each address SDH?

7. Do you feel this course provided value?

8. What additional thoughts do you want us to know about this course?

Table 2 Individual Group Evaluation Questions

\section{B. Data Collection and Analysis}

All data was collected throughout the course using pen and paper surveys and drawings (i.e. concept maps). Pre-tests and post-tests were conducted using the ICCAS to measure change in student's perception of their interprofessional competencies across the duration of the interprofessional course. With a small class, analysis of the ICCAS was limited to descriptive statistics and a paired sample t-test of summary scores. Finally, the course evaluation was primarily focused on the individual group evaluations that explored both individual and member collaborations, as well as future application of knowledge.

A critical discourse analysis ("CDA") was conducted on the individual group evaluations. Critical discourse is an approach that analyzes elements of verbal and non-verbal engagements and the dynamics of power associated to each. ${ }^{28}$ Elements of discourse include linguistics (i.e. words, phrases), interpersonal interactions, situational communication expectations, meaning, and

25 Douglas Archibald, David Trumpower \& Colla J. MacDonald, Validation of the Interprofessional Collaborative Competency Attainment Survey ("ICCAS”), 28 J. INTERPROFESSIONAL CARE 553, 553-58 (2014).

${ }^{26} \mathrm{Id}$.

${ }^{27}$ See Table 2.

${ }^{28}$ Encarnacion Hidalgo Tenorio, Critical Discourse Analysis: An Overview, 10 Nordic J. of Eng. Studies 183, 184 (2011). 
making. ${ }^{29}$ CDA aims to "raise[] awareness concerning the strategies used in establishing, maintaining and reproducing (a)symmetrical relations of power as enacted by means of discourse. ${ }^{30}$ Critical discourse analysis goes beyond description of content and explanation to include socio-political perspectives for analysis of, and application to problem-solve world problems. ${ }^{31}$ This critical analysis of power by CDA was found to be an appropriate methodology for studying the dynamics of interprofessional collaboration between students. ${ }^{32}$

In this study, the CDA was guided by Gee's Seven Building Tasks, with an emphasis on the identities and relationship building tools. In CDA, discourse is constructed by the seven building tasks: significance, practices (activities), identities, relationships, politics (the distribution of social goods), connections, and sign systems and knowledge. ${ }^{33}$ The tasks' relationships and identities were the focus of this study. Each tool had six subquestions that generated nodes; twenty-six nodes were used in this analysis: relative position, role, and characteristics.

\begin{tabular}{|c|c|c|}
\hline $\begin{array}{l}\text { Relative Position } \\
\text { - MSW for MSW } \\
\text { MSW for JD } \\
\text { MSW for MPH } \\
\text { MSW } \\
\text { Miscellaneous } \\
\text { JD for JD } \\
\text { JD for MSW } \\
\text { JD for MPH } \\
\text { JD for Miscellaneous } \\
\text { MPH for MPH } \\
\text { MPH for MSW } \\
\text { MPH for JD } \\
\text { MPH } \\
\text { miscellaneous }\end{array}$ & $\begin{array}{l}\text { Role } \\
\text { - MSW about MSW } \\
\text { - Other about MSW } \\
\text { - JD about JD } \\
\text { - Other about JD } \\
\text { - MPH about MPH } \\
\text { - Other about MPH } \\
\text { - Other about } \\
\text { miscellaneous }\end{array}$ & $\begin{array}{l}\text { Characteristics } \\
\text { - MSW about MSW } \\
\text { - Other about MSW } \\
\text { - JD about JD } \\
\text { - Other about JD } \\
\text { - MPH about MPH } \\
\text { - Other about MPH } \\
\text { - Other about } \\
\text { miscellaneous }\end{array}$ \\
\hline
\end{tabular}

29 James Paul Gee, An Introduction to Discourse Analysis: TheOry AND Method, 147167 (4th ed. 2011). 147-167.

30 Tenorio, supra note 28.

31 Gee, An Introduction to Discourse Analysis: Theory And Method, 68-69 (3rd ed. 2011).

32 Wael Haddara, \& Lorelei Lingard (2013). Are We All on the Same Page? A Discourse Analysis of Interprofessional Collaboration, Academic Medicine, 88(10), ACAD. MED. 1509 (2013).

${ }^{33}$ GEE, supra note 31 at 121. 


\section{Table 3. Critical Discourse Analysis Building Tasks and Nodes*}

Nodes were synthesized into emerging themes by the research group in three stages. First, each of the four researchers examined the data identifying nodes individually. Then, researchers met to compare individual coding of nodes to create a consensus. The final stage was a series of synthesizing codes into emerging themes.

\section{RESUlT}

The evaluation of this interprofessional course illuminated the challenges to and benefits of interprofessional education. ICCAS pre-test and post-test demonstrated an increase in interprofessional competencies among students. Using Gee's analysis as a guide, researchers identified three overarching themes with additional subthemes in the group evaluations. Each theme has implications for further education in an interprofessional setting in the macro arena.

\section{A. Interprofessional Collaborative Competencies Attainment Survey (“ICCAS”)}

A paired samples t-test showed a significant change in ICCAS scores between the pre- and post-test $(t=-7.971, p<.001)$. Mean scores increased $(+.88)$ and standard deviation decreased (.19) between the pre- and post-test indicating improved self-perception of collaborative competencies over the course of the semester. ${ }^{34}$ This trend was also reflected in the results of each subscale. ${ }^{35}$ One exception was noted of a student who reported a decrease on questions under the "patient/family-centered approach" subscale. The researchers posit that this decrease may be due to the macro setting of the course with the client as organization rather than person, creating confusion.

\begin{tabular}{lllllll}
\hline & Pre-test & \multicolumn{3}{c}{ Post-test } & \multicolumn{3}{c}{ Change } \\
Scale and Subscales & $M$ & $S D$ & $M$ & $S D$ & $M$ & $S D$ \\
\hline ICCAS & 5.58 & .59 & 6.46 & .40 & +.88 & -.19 \\
Communication & 5.76 & .74 & 6.58 & .49 & +.82 & -.25 \\
Collaboration & 5.37 & .90 & 6.54 & .56 & +1.17 & -.34 \\
Roles and Responsibilities & 5.69 & .66 & 6.69 & .37 & +1.00 & -.29 \\
Collaborative & 5.37 & .96 & 5.92 & .97 & +.55 & +.01 \\
$\begin{array}{l}\text { Patient/Family-Centered } \\
\text { Approach }\end{array}$ & & & & & & \\
$\begin{array}{l}\text { Conflict } \\
\text { Management/resolution }\end{array}$ & 5.96 & .72 & 6.63 & .51 & +.67 & -.21 \\
Team Functioning & 5.00 & 1.00 & 6.44 & .77 & +1.44 & -.23 \\
\hline
\end{tabular}

Table 4 ICCAS Subscales Pre-test and Post-test*

\footnotetext{
${ }^{*} \mathrm{MSW}=$ Social Work, JD $=$ Law, MPH $=$ Public Health.

${ }^{34}$ See Table 4.

${ }^{35} I d$.

* Based on summary scores for scale and subscales
} 


\section{Theme 1: Professional Hegemony Exists Between the Professional Students}

Similar to the need for legal partners to understand how the medical profession works when collaborating, ${ }^{36}$ collaboration between professions was advantageous for students addressing social determinants of health to learn about related law and policy from multiple perspectives. Because of the importance placed on legal knowledge in these collaborative groups, a hegemony was formed with social work and public health students deferring to law students who unquestionably took leadership. This was evident in the dialogue about working with students in other professions. Social worker students "sought consensus about every task while the law student sometimes worked on their own and then told the group about it later." One social work students spoke candidly about their frustrations when working in their group:

Social workers, based on our group experience, definitely have a voice and want to be heard - but in a way that is accessible, understandable, and reflective of all voices heard. We are advocates for others and ourselves and do not want to be steamrolled or have others stereotype us as unintelligent or have to defend our actions or methods of decision-making. But, maybe that falls on us social workers to play a bigger role in being recognized as a valid and knowledgeable profession.

In order to create a successful collaboration where contributions by each member are valued, underlying hegemony needs to be addressed and reconciled. As these students have expressed, hegemony breeds frustration, miscommunication, and potentially worse in practice where peoples' lives are directly affected.

\section{Theme 2: Students Perceive Professional Content Expertise as the Most Important Knowledge}

When collaborative skills were learned and applied, students experienced benefits that will undoubtedly enrich their future practice. Benefits of the interprofessional education course were twofold. On its face, the course was designed to increase students' knowledge of social determinants of health and related policy actions. More so, however, the course was intended to increase students' collaborative skills in order to prepare them to work in collaborative settings through hands-on experience with peers and community agencies. Despite challenges, student perspectives support the claim that both goals were attained in this interprofessional course. ${ }^{37}$

\footnotetext{
${ }^{36}$ Benfer et al., supra note 13 at 240-41.

${ }^{37}$ See Table 5.
} 


\section{Increased Awareness of SDOH and Policy}

- [This course] strengthened my understanding of system building (MSW)

- [I now have a] much better understanding of how to interpret policy and what it could mean for citizens (MSW)

- [My] knowledge of SDOH [has] improved (MSW)

- [This course] didn't increase my knowledge but did provide insight of how to address them $(\mathrm{SDOH})$ in practice (JD)

- [This course] gave another perspective [on $\mathrm{SDOH}](\mathrm{MSW})$

\section{Increased Collaborative Skills}

- [This course] strengthened my understanding of...interactions between professions (MSW)

- [I have an] increased appreciation of other professions now (MSW)

- [This course] made me understand how to communicate effectively with my group (JD)

- [C]onsulting other professions will enhance my [understanding of SDOH] (MSW)

- $\left[\begin{array}{ll}\mathrm{I} & \mathrm{am}\end{array}\right]$ better prepared to work in organizations with other professionals as result of IPE (JD/MPH)

\section{Table 5 Course Goals and Student Perspectives*}

\section{Theme 3: Learning Collaborative Skills Needs to be Intentional and Does not Occur Effectively Simply by Working Together}

A consistent theme among students was the need for learning particular skills in order to collaborate productively. Students expressed a desire for a shared understanding of professional roles and abilities. In reflection, students commented with surprise about the knowledge other professions possessed that would have been useful had they been known previously aware. One social work student stated, "I wish both professions had a deeper understanding of how the others worked." This statement speaks to the importance and lack of role development such as an individual's relevant knowledge, previous experience, and potential contributions.

The researchers described the necessary skills for successful interprofessional collaboration as collaborative skills. Students expressed a particular interest in collaborative skills with emphasis on decision-making styles, problem-solving, and conflict resolution-"[Group members] did not know how to address conflict." Furthermore, what skills were present among students differed in ability or approach. However, they "resolved situations despite differences in legal skills." Law students also mentioned differences in problem-solving skills between social work and law students: "[The class] made me understand how to communication effectively with my group and work certain situations out despite the differences in our legal skills."

\section{B. Challenges to Interprofessional Collaboration Among Students}

It became apparent that collaboration was not naturally occurring but rather required intentional work by each student. One social work student noted, "each member has to be willing to work together and compromise to reach goal." The process of building those relationships was described as "not easy." The use of technology (emails, google docs) was identified by students as

\footnotetext{
${ }^{*} \mathrm{MSW}=$ Social work student, JD $=$ Law student, MPH $=$ Public health student.
} 
a barrier to communication within some groups. One social work student questioned if group members were being snide in an email.

Communication between students within groups was distinctly varied by a student's profession. Social work students commented on miscommunication and confusion about tone, expressing that law students communicated differently than social work students. Some expressed specific frustration at trying to communicate with law students. Interestingly, none of the law students noted differences in communication but rather remarked on the good communication within their group. These discrepancies may be due to a lack of awareness on law students and/or lack of social work students voicing concerns about group communication.

While the majority of law students expressed no enhancement of knowledge and had more to contribute to their group members than the reverse-"it was clear that law students had more tools/training." social work students approached differences in knowledge from a strength-based perspective-"everyone is equal, just with different skills sets." It is interesting to note that the law students focused on content, not process, in their statements about knowledge attainment.

\section{DISCUSSION}

While literature on interprofessional education and collaboration is present, little exists on interprofessional education and collaboration in the macro arena, warranting more literature and evaluation. This interprofessional course was designed to address this gap in education and evaluation. The ICCAS is a standard instrument in interprofessional collaboration; however, the lack of macro-level collaboration measured in the instrument reflects the dominant micro focus of interprofessional education and collaboration. In response, the researchers intend to pilot and evaluate an adaptation of the ICCAS that includes a macro perspective to be used in future iterations of this interprofessional course to capture multiple levels of collaborative competencies. Furthermore, instruments specific to assessing macro-level interprofessional skills are warranted for future evaluation and towards best practices of macro-level interprofessional education and collaboration. Additionally, interprofessional hegemony, a key discovery in the findings, is an important topic of future research to further analyze and discover the source in order to dismantle the hindrance to collaboration.

\section{CONCLUSION}

Interprofessional education plays an integral role in the future for public health, law, social work, nursing, medicine, and other professions facing social issues. With a disappearing separation between classroom and practice, IPEC enables innovation and creativity in critical thinking and engagement in problem-solving that cultivates future leaders. ${ }^{38}$ Law students can become better lawyers through social justice curriculum, ${ }^{39}$ particularly integrating public health law into their advocacy. ${ }^{40}$ Review of the existing literature and data from this first class will inform future iterations of this interprofessional course and contribute to the dearth of knowledge on macro arena interprofessional education and curriculum.

${ }^{38}$ Benfer et al., supra note 13 at 255.

${ }^{39} \mathrm{Id}$.

${ }^{40}$ See Linda L. Chezem, Public Health Law \& Equal Access to Justice in Rural America, 59

S.D. L. REV. 529 (2014). 
The researchers sought to answer how students understand their role as future professionals and how students navigate the collaborative process within interprofessional education. While collaborative competencies were increased, the results showed that students would benefit from additional collaborative skills and role development. This study was merely an introductory exploration of interprofessional education and collaboration in the macro arena. Evaluation showed the curriculum to be effective in increasing interprofessional collaborative skills and highlighted areas for further development. It is the hope of the researchers that this introduction will spark a dialogue and for future research addressing interprofessional collaboration and evaluation in the macro arena. 